Pak. j. sci. ind. res. Ser. A: phys. sci. 201255 (3) 149-154

\title{
The Tensile Properties of Polyester / Cotton Blended Yarn as Affected by Different Process Variables of Murata Vortex Spinning System
}

\author{
Muhammad Qamar Tusief*, Nasir Mahmood and Abdul Haleem Anjum \\ Department of Fibre and Textile Technology, University of Agriculture, Faisalabad, Pakistan
}

(received August 15, 2011; revised October 27, 2011; accepted October 31, 2011)

\begin{abstract}
The quality of Murata Vortex Spinning (MVS) yarn especially its tensile properties is significantly affected by different process settings (variables) of the system. The research was carried to optimize MVS process variables like yarn delivery speed, spindle diameter and the distance between front roll and spindle to achieve better tensile properties of polyester / cotton blend yarn. The results revealed that spindle diameter, the distance between front roll and spindle and blend ratio all have significant effect upon tensile properties of MVS yarn.
\end{abstract}

Keywords: Murata Vortex Spinning, tensile properties, blend ratio, delivery speed, spindle diameter

\section{Introduction}

Murata Vortex Spinning (MVS) was introduced at the 1997 Osaka International Textile Machinery Show. The air vortex spinning method used by the MVS takes drawn cotton sliver and drafts it to the desired yarn count (fineness) using a four roller / apron drafting system. The drafted fibres are then sucked into a nozzle where a high speed 'vortex' air current wraps the fibres around the outside of a hollow stationary spindle. A vacuum around the base of the spindle acts to comb out shorter fibres and neps. Fibres are pulled down a shaft that runs through the middle of the spindle. Yarn twist is inserted as the fibres swirl around the apex of the spindle before being pulled down the spindle shaft (Gordon, 2002).

Murata Vortex Spinning is best judged as a development of jet spinning specifically created to overcome the limitations of the shorter length of cotton fibres. Airjet spinning in the past has been limited to predominantly man-made staple fibres that are consistently longer and more uniform in length. The major marketing feature of MVS is that it is capable of spinning uncombed cotton slivers into acceptable yarns at speeds that are significantly higher than with any other system. The yarn structure is different from jet-spun yarn with many more wrapper fibres. The main concern is that there is excessive fibre loss using this spinning machine. Fibre loss values in excess of $14 \%$ have been reported by Gordon (2002), although mostly these fibres represent

*Author for correspondence; E-mail: qamartosief@yahoo.com short fibres i.e. less than $12.5 \mathrm{~mm}(1 / 2 \mathrm{inch})$. As such most of this is short fibre it does not contribute to yarn quality. The MVS was introduced with a remarkable processing speed of 350-400 $\mathrm{m} / \mathrm{min}$, with later version capable of speeds up to $450 \mathrm{~m} / \mathrm{min}$. Oxenham (2003) has noted successful spinning systems historically have had a significant increase in production speed within a few years of introduction.

The distance between the front roller and the spindle of the MVS is critical since it determines the number of wrapping fibres. If this distance is shortened both ends of fibres remain tightly assembled, resulting in fewer open ended fibres and less wrapping fibres. The result of this is yarn with mostly parallel core fibres held with fewer wrapper fibres, as in the case of air-jet yarn. Yarn evenness and imperfections are typically better since there is less chance of losing control of fibres during the bundling of the parallel core fibres, which forms the main part of the yarn with a few wrapper fibres. Furthermore, waste is less because of the better fibre control. The yarn has less hairiness and a leaner appearance. If the distance between the roller and spindle is increased, the number of wrapper fibres increases, but there is also less fibre control. The resultant yarn is softer due to increasing wrapper fibres and is sometimes more hairy.

The diameter of the spindle bore determines the tightness of the wrappings. A small spindle diameter gives less freedom to the fibre bundle to expand as it enters the spindle. This generates higher friction between fibres 
and the bore lip, and leads to tighter wrapping, higher twist and in turn, denser yarns with less hair. Larger spindle bore diameters give the fibre bundle more freedom to move inside the spindle. This means some twist is lost, wrappings become looser and the yarn becomes bulky and more hairy (Basal and Oxenham, 2006). The influence of different polyester / cotton blends, yarn delivery speed, spindle diameter and the distance between front roll and spindle upon the quality parameters of MVS yarn have previously been reported by Ortlek et al. (2008); Basal and Oxenham (2006) and Ortlek and Ulku (2005). However, integrated effect of manipulation of all these factors on yarn quality has not been assessed. Present study evaluates the performance of different levels of polyester / cotton blend ratios, yarn speed, spindle diameter and the distance between front roll and spindle. The objective of this evaluation is to optimize the quality of the yarn with respect to its tensile properties.

\section{Materials and Methods}

The present study was initiated in the Department of Fibre and Textile Technology, University of Agriculture, Faisalabad, and mainly conducted at a cotton spinning mill at Sheikhupura, Pakistan. The processing details and methods applied to record the effect of multiple polyester / cotton blends, delivery speed, spindle diameter and distance between front roll and spindle upon the tensile properties of ultimate yarn are described below.
Material used. Lint sample of cotton variety MNH-93 and polyester staple fibre were collected from the running stock of the mill. The cotton fibre properties are given in the Table 1 while the polyester fibre properties are given in Table 2 .

Spinning process. Lint cotton of MNH-93 variety and polyester staple fibre were processed separately in blow room and carding section at the normal machinery adjustments. The card slivers of polyester and cotton were fed to breaker and finisher drawing frames in order to prepare the blended sliver according to the respective ratios as given in Table 3, then processed at Murata Vortex Spinner (MVS-8R2) for each of technical settings listed in the Table 3, while keeping air pressure unchanged.

The samples of $\mathrm{Ne} 30^{\mathrm{s}}$ (20 tex) yarn prepared with every combination ( 252 combinations) and were tested for the following characteristics.

Tensile properties of yarn. Tensile properties i.e. single yarn strength, elongation and rupture per kilometer were measured with an Uster Tensorapid-3, which works on the principle of constant rate of extension (CRE) as described in ASTM standards; D2256-02 (2008).

Data analysis. The data thus obtained were analyzed statistically by an analysis of variance and using Duncan's Multiple Range (DMR) test for individual comparisons as suggested by Montgomery (2009). Data analysis was completed using SPSS (Statistical

Table 1. Physical characteristics of cotton variety MNH-93

\begin{tabular}{|c|c|c|c|c|c|c|c|}
\hline No. & $\begin{array}{l}\text { Fibre span } \\
\text { length } \\
(\mathrm{mm})\end{array}$ & $\begin{array}{l}\text { Uniformity } \\
\text { ratio } \\
(\%)\end{array}$ & $\begin{array}{l}\text { Fibre strength } \\
(\mathrm{g} / \text { tex })\end{array}$ & $\begin{array}{l}\text { Fibre fineness } \\
(\mu \mathrm{g} / \text { inch })\end{array}$ & $\begin{array}{l}\text { Maturity index } \\
(\%)\end{array}$ & $\begin{array}{l}\text { Trash content } \\
(\%)\end{array}$ & $\begin{array}{l}\text { Short fibre } \\
\text { content }\end{array}$ \\
\hline 1 & 28.75 & 49.10 & 28.20 & 4.30 & 76 & 7.4 & 11.4 \\
\hline 2 & 27.95 & 50.10 & 28.90 & 4.20 & 81 & 6.9 & 11.9 \\
\hline 3 & 28.15 & 49.00 & 28.30 & 4.25 & 77 & 7.8 & 11.8 \\
\hline 4 & 28.20 & 50.30 & 28.40 & 3.95 & 79 & 7.2 & 11.2 \\
\hline 5 & 27.85 & 49.60 & 29.30 & 4.50 & 76 & 7.9 & 10.9 \\
\hline 6 & 28.39 & 49.20 & 28.70 & 4.18 & 80 & 8.1 & 11.6 \\
\hline 7 & 28.32 & 48.90 & 27.90 & 4.30 & 78 & 7.5 & 10.8 \\
\hline 8 & 28.12 & 49.80 & 28.00 & 4.15 & 79 & 7.3 & 11.1 \\
\hline 9 & 28.41 & 49.20 & 28.10 & 4.12 & 80 & 7.4 & 10.7 \\
\hline 10 & 28.12 & 50.20 & 28.20 & 4.39 & 81 & 6.8 & 10.9 \\
\hline Mean & 28.21 & 49.54 & 28.40 & 4.22 & 79 & 7.43 & 11.2 \\
\hline SD & 0.25 & 0.530 & 0.440 & 0.15 & 1.88 & 0.279 & 0.427 \\
\hline $\mathrm{CV} \%$ & 0.92 & 1.07 & 1.55 & 3.46 & 2.37 & 0.62 & 3.81 \\
\hline
\end{tabular}

$\mathrm{SD}=$ standard deviation; $\mathrm{CV}=$ coefficient of variation 
Table 2. Physical characteristics of polyester fibres

\begin{tabular}{ll}
\hline \hline Staple length & $38 \mathrm{~mm}$ \\
Denier & 1.28 \\
Tenacity & $7 \mathrm{~g} / \mathrm{den}$ \\
Elongation & $19 \%$ \\
Moisture regain & $38 \%$ \\
\hline \hline
\end{tabular}

Table 3. Spinning variables for the study

\begin{tabular}{llll}
\hline \hline $\begin{array}{l}\text { Blend ratio } \\
\text { (Polyester: } \\
\text { cotton) }\end{array}$ & $\begin{array}{l}\text { Delivery } \\
\text { speed } \\
(\mathrm{m} / \mathrm{min})\end{array}$ & $\begin{array}{l}\text { Spindle } \\
\text { diameter } \\
(\mathrm{mm})\end{array}$ & $\begin{array}{l}\text { Distance between } \\
\text { front roll and } \\
\text { spindle }(\mathrm{mm})\end{array}$ \\
\hline $\mathrm{B}_{1}=80: 20$ & $\mathrm{~S}_{1}=300$ & $\mathrm{D}_{1}=1.2$ & $\mathrm{~A}_{1}=19.5$ \\
$\mathrm{~B}_{2}=70: 30$ & $\mathrm{~S}_{2}=320$ & $\mathrm{D}_{2}=1.4$ & $\mathrm{~A}_{2}=20.0$ \\
$\mathrm{~B}_{3}=60: 40$ & $\mathrm{~S}_{3}=340$ & $\mathrm{D}_{3}=1.6$ & $\mathrm{~A}_{3}=20.5$ \\
$\mathrm{~B}_{4}=50: 50$ & $\mathrm{~S}_{4}=360$ & - & - \\
$\mathrm{B}_{5}=40: 60$ & - & - & - \\
$\mathrm{B}_{6}=30: 70$ & - & - & - \\
$\mathrm{B}_{7}=20: 80$ & - & - & - \\
\hline \hline
\end{tabular}

Programme for Social Science) micro-computer statistical programme.

\section{Results and Discussion}

Single yarn strength. The analysis of variance and comparison of individual means regarding single yarn strength are given in the Tables 4 and $4 \mathrm{a}$. The analysis indicates that the effect of blend ratio (B) and spindle diameter (D) are highly significant while the effect of delivery speed (S) and distance between front roll and spindle (A) as well as all the interactions are nonsignificant for single yarn strength.

Duncan's multiple range test and the comparison of individual treatment means for blend ratio are presented in Table 4a shows that the mean values of single yarn strength for $\mathrm{B}_{1}, \mathrm{~B}_{2}, \mathrm{~B}_{3}, \mathrm{~B}_{4}, \mathrm{~B}_{5}, \mathrm{~B}_{6}$ and $\mathrm{B}_{7}$ are 322.66 , $310.45,302.78,286.55,275.19,262.63$ and $250.83(\mathrm{~g})$, respectively. Each successive value is significantly different from the other. $\mathrm{B}_{1}$ gave the maximum single yarn strength indicating that as the percentage of polyester decreased, yarn strength also decreased. These results support the research findings reported by Nawaz et al. (1999) that there is a gradual decrease in MVS yarn strength as the share of polyester fibre in the blend decreases. Similarly in other studies it has been reported that the air-jet spun and ring spun yarn tensile properties improved gradually as the share of polyester in the blend was increased (Shahzad, 2003; Hussain, 1981).
Duncan's multiple range test and the comparison of individual treatment means for spindle diameter presented in Table $4 \mathrm{a}$ shows the mean values of single yarn strength for $D_{1}, D_{2}$ and $D_{3}$ are $290.13,286.92$ and $284.84(\mathrm{~g})$, respectively. These values are significantly different from one another. $\mathrm{D}_{1}$ gave the maximum value indicating that, as the spindle diameter increased the single yarn strength value decreased. These results correlate with the findings of Oxenham (2003) that a small spindle diameter gives less freedom to the fibre bundle to expand as it enters the spindle. This generates

Table 4. Analysis of variance for single yarn strength

\begin{tabular}{llllll}
\hline \hline Source & DF & SS & MS & F & P \\
\hline B & 6 & 148031 & 24671.8 & 4253.7 & $0.0000^{* *}$ \\
S & 3 & 12.35 & 4.11 & 0.70 & $0.6532^{\mathrm{NS}}$ \\
$\mathrm{D}$ & 2 & 1195 & 597.4 & 103.34 & $0.0000^{* *}$ \\
$\mathrm{~A}$ & 2 & 11.33 & 5.66 & 0.97 & $0.5481^{\mathrm{NS}}$ \\
$\mathrm{B} \times \mathrm{S}$ & 18 & 139 & 7.7 & 1.33 & $0.1939^{\mathrm{NS}}$ \\
$\mathrm{B} \times \mathrm{D}$ & 12 & 46 & 3.8 & 0.67 & $0.7785^{\mathrm{NS}}$ \\
$\mathrm{B} \times \mathrm{A}$ & 12 & 69 & 5.8 & 1.00 & $0.4566^{\mathrm{NS}}$ \\
$\mathrm{S} \times \mathrm{D}$ & 6 & 49 & 8.2 & 1.42 & $0.2197^{\mathrm{NS}}$ \\
$\mathrm{S} \times \mathrm{A}$ & 6 & 35 & 5.9 & 1.02 & $0.4212^{\mathrm{NS}}$ \\
$\mathrm{D} \times \mathrm{A}$ & 4 & 30 & 7.6 & 1.31 & $0.2747^{\mathrm{NS}}$ \\
$\mathrm{B} \times \mathrm{S} \times \mathrm{D}$ & 36 & 218 & 6.1 & 1.05 & $0.4250^{\mathrm{NS}}$ \\
$\mathrm{B} \times \mathrm{S} \times \mathrm{A}$ & 36 & 201 & 5.6 & 0.96 & $0.5381^{\mathrm{NS}}$ \\
$\mathrm{B} \times \mathrm{D} \times \mathrm{A}$ & 24 & 126 & 5.2 & 0.91 & $0.5933^{\mathrm{NS}}$ \\
$\mathrm{S} \times \mathrm{D} \times \mathrm{A}$ & 12 & 57 & 4.7 & 0.82 & $0.6330^{\mathrm{NS}}$ \\
$\mathrm{B} \times \mathrm{S} \times \mathrm{D} \times \mathrm{A}$ & 72 & 378 & 5.2 & 0.89 & $0.4838^{\mathrm{NS}}$ \\
$\mathrm{E} r$ ror & 756 & 4384.8 & 5.8 & - & - \\
Total & 1007 & 154982.4 & - & - & - \\
\hline \hline
\end{tabular}

** = highly significant; $\mathrm{NS}=$ non-significant; $\mathrm{CV} \%=0.83$

Table 4a. Comparison of individual treatment means for single yarn strength $(\mathrm{g})$

\begin{tabular}{llll}
\hline \hline $\begin{array}{l}\text { Blend ratio } \\
\text { (B) }\end{array}$ & $\begin{array}{l}\text { Delivery } \\
\text { speed } \\
\text { (S) }\end{array}$ & $\begin{array}{l}\text { Spindle } \\
\text { diameter } \\
\text { (D) }\end{array}$ & $\begin{array}{l}\text { Distance between } \\
\text { front roll } \\
\text { and spindle } \\
\text { (A) }\end{array}$ \\
\hline $\mathrm{B}_{1}=322.66 \mathrm{a}$ & $\mathrm{S}_{1}=287.93$ & $\mathrm{D}_{1}=290.13 \mathrm{a}$ & $\mathrm{A}_{1}=286.88$ \\
$\mathrm{~B}_{2}=310.45 \mathrm{~b}$ & $\mathrm{~S}_{2}=287.21$ & $\mathrm{D}_{2}=286.92 \mathrm{~b}$ & $\mathrm{~A}_{2}=287.26$ \\
$\mathrm{~B}_{3}=302.78 \mathrm{c}$ & $\mathrm{S}_{3}=288.80$ & $\mathrm{D}_{3}=284.84 \mathrm{c}$ & $\mathrm{A}_{3}=287.76$ \\
$\mathrm{~B}_{4}=286.55 \mathrm{~d}$ & $\mathrm{~S}_{4}=287.00$ & - & - \\
$\mathrm{B}_{5}=275.19 \mathrm{e}$ & - & - & - \\
$\mathrm{B}_{6}=262.63 \mathrm{f}$ & - & - & - \\
$\mathrm{B}_{7}=250.83 \mathrm{~g}$ & - & - & - \\
\hline \hline
\end{tabular}

Any two values not sharing a letter in common differ significantly at 0.05 level of probability. 
higher friction between fibres and leads to tighter wrapping of fibres around the yarn core, higher twist and denser yarns with less hair.

Rupture per kilometer (RKM). The statistical analysis of variance and comparison of individual means regarding rupture per $\mathrm{km}(\mathrm{RKM})$ or yarn tenacity are given in Tables 5 and 5a. The results indicate that the effect of blend ratio (B) and spindle diameter (D) are highly significant while the effect of delivery speed (S) and distance between front roll and spindle (A) as well as all interactions are non-significant for rupture per kilometer.

Duncan's multiple range test and the comparison of individual treatment means for blend ratio presented in Table $5 \mathrm{a}$ shows that the mean values of RKM for $\mathrm{B}_{1}$, $\mathrm{B}_{2}, \mathrm{~B}_{3}, \mathrm{~B}_{4}, \mathrm{~B}_{5}, \mathrm{~B}_{6}$ and $\mathrm{B}_{7}$ are 21.28, 20.16, 19.32, 18.15, 17.26, 16.48 and 15.18 (g/tex), respectively. These values are significantly different from one another. $\mathrm{B}_{1}$ gave the maximum value indicating that as the percentage of polyester increased the RKM value also increased. These findings are in line with other results in spinning studies (Shahzad, 2003; Hussain, 1981) that shows that as the share of polyester in the blend decreased, the RKM value also decreased.

Table 5. Analysis of variance for rupture per kilometer (RKM)

\begin{tabular}{llllll}
\hline \hline Source & DF & SS & MS & F & $P$ \\
\hline B & 6 & 992.42 & 165.404 & 7191.43 & $0.0000^{* *}$ \\
S & 3 & 0.19 & 0.063 & 2.73 & $0.2025^{\mathrm{NS}}$ \\
D & 2 & 707.77 & 353.884 & 15385.2 & $0.0000^{* *}$ \\
A & 2 & 0.10 & 0.05 & 2.17 & $0.1973^{\mathrm{NS}}$ \\
$\mathrm{B} \times \mathrm{S}$ & 18 & 0.26 & 0.014 & 0.62 & $0.8685^{\mathrm{NS}}$ \\
$\mathrm{B} \times \mathrm{D}$ & 12 & 0.12 & 0.010 & 0.45 & $0.9350^{\mathrm{NS}}$ \\
$\mathrm{B} \times \mathrm{A}$ & 12 & 0.29 & 0.024 & 1.06 & $0.4059^{\mathrm{NS}}$ \\
$\mathrm{S} \times \mathrm{D}$ & 6 & 0.13 & 0.022 & 0.96 & $0.4612^{\mathrm{NS}}$ \\
$\mathrm{S} \times \mathrm{A}$ & 6 & 0.16 & 0.027 & 1.20 & $0.3178^{\mathrm{NS}}$ \\
$\mathrm{D} \times \mathrm{A}$ & 4 & 0.19 & 0.048 & 2.09 & $0.1909^{\mathrm{NS}}$ \\
$\mathrm{B} \times \mathrm{S} \times \mathrm{D}$ & 36 & 0.39 & 0.011 & 0.47 & $0.9930^{\mathrm{NS}}$ \\
$\mathrm{B} \times \mathrm{S} \times \mathrm{A}$ & 36 & 0.90 & 0.025 & 1.09 & $0.3756^{\mathrm{NS}}$ \\
$\mathrm{B} \times \mathrm{D} \times \mathrm{A}$ & 24 & 0.54 & 0.023 & 0.98 & $0.5005^{\mathrm{NS}}$ \\
$\mathrm{S} \times \mathrm{D} \times \mathrm{A}$ & 12 & 0.35 & 0.029 & 1.28 & $0.2474^{\mathrm{NS}}$ \\
$\mathrm{B} \times \mathrm{S} \times \mathrm{D} \times \mathrm{A}$ & 72 & 1.25 & 0.0173 & 0.75 & $0.4235^{\mathrm{NS}}$ \\
Error & 756 & 17.38 & 0.023 & - & - \\
Total & 1007 & 1722.44 & - & - & - \\
\hline ** highly & significant; NS $=$ non-significant; CV\% $=0.84$
\end{tabular}

Duncan's multiple range test and the comparison of individual treatment means for spindle diameter presented in Table 5a, it shows that mean values of RKM for $\mathrm{D}_{1}, \mathrm{D}_{2}$ and $\mathrm{D}_{3}$ are 20.30, 18.28 and 16.20 ( $\mathrm{g} /$ tex), respectively. $\mathrm{D}_{1}$ gave the maximum value indicating that as the spindle diameter increased the RKM value decreased. These results are closely related to the observations that the fibre bundle has more freedom to move inside the spindle with a large spindle diameter and therefore some twist is lost, wrappings become looser and the yarn becomes bulky and more hairy (Basal and Oxenham, 2006).

Table 5a. Comparison of individual treatment means for rupture per kilometer (g/tex)

\begin{tabular}{llcl}
\hline \hline $\begin{array}{l}\text { Blend ratio } \\
(\mathrm{B})\end{array}$ & $\begin{array}{l}\text { Delivery } \\
\text { speed } \\
(\mathrm{S})\end{array}$ & $\begin{array}{l}\text { Spindle } \\
\text { diameter } \\
(\mathrm{D})\end{array}$ & $\begin{array}{l}\text { Distance } \\
\text { between } \\
\text { front roll } \\
\text { and spindle } \\
(\mathrm{A})\end{array}$ \\
\hline $\mathrm{B}_{1}=21.284 \mathrm{a}$ & $\mathrm{S}_{1}=18.422$ & $\mathrm{D}_{1}=20.306 \mathrm{a}$ & $\mathrm{A}_{1}=18.129$ \\
$\mathrm{~B}_{2}=20.164 \mathrm{~b}$ & $\mathrm{~S}_{2}=18.322$ & $\mathrm{D}_{2}=18.288 \mathrm{~b}$ & $\mathrm{~A}_{2}=18.276$ \\
$\mathrm{~B}_{3}=19.326 \mathrm{c}$ & $\mathrm{S}_{3}=18.216$ & $\mathrm{D}_{3}=16.201 \mathrm{c}$ & $\mathrm{A}_{3}=18.389$ \\
$\mathrm{~B}_{4}=18.158 \mathrm{~d}$ & $\mathrm{~S}_{4}=18.099$ & - & - \\
$\mathrm{B}_{5}=17.261 \mathrm{e}$ & - & - & - \\
$\mathrm{B}_{6}=16.484 \mathrm{f}$ & - & - & - \\
$\mathrm{B}_{7}=15.178 \mathrm{~g}$ & - & - & - \\
\hline \hline
\end{tabular}

Any two values not sharing a letter in common differ significantly at 0.05 level of probability.

Yarn elongation. The statistical analysis of variance and comparison of individual means regarding yarn elongation are given in Tables 6 and 6a. The results indicate the effect of blend ratio (B) and distance between front roll and spindle (A) are highly significant, while the effect of delivery speed (S) and spindle diameter (D) as well as all the interactions are non-significant for the yarn elongation.

Duncan's multiple range test and the comparison of individual treatment means for blend ratio presented in Table 6a show that mean values of yarn elongation for $\mathrm{B}_{1}, \mathrm{~B}_{2}, \mathrm{~B}_{3}, \mathrm{~B}_{4}, \mathrm{~B}_{5}, \mathrm{~B}_{6}$ and $\mathrm{B}_{7}$ are 8.75, 8.46, 8.20, 7.86, 7.40, 7.04 and $6.72(\%)$, respectively. These values are significantly different from one another. $\mathrm{B}_{1}$ gave the maximum value indicating that as the percentage of polyester increased, the yarn elongation value also increased. These results also support the findings that as the share of polyester in the blend decreases, the value of elongation also decreases. 
Table 6. Analysis of variance for yarn elongation

\begin{tabular}{|c|c|c|c|c|c|}
\hline Source & $\mathrm{DF}$ & SS & MS & F & $\mathrm{P}$ \\
\hline B & 6 & 122.306 & 20.3843 & 2018.24 & $0.0000^{* *}$ \\
\hline S & 3 & 0.035 & 0.0116 & 1.14 & $0.3841^{\mathrm{N} . \mathrm{S}}$ \\
\hline $\mathrm{D}$ & 2 & 0.051 & 0.0255 & 2.52 & $0.1183^{\mathrm{N} . \mathrm{S}}$ \\
\hline A & 2 & 4.365 & 2.1823 & 216.60 & $0.0000^{* *}$ \\
\hline $\mathrm{B} \times \mathrm{S}$ & 18 & 0.190 & 0.0105 & 1.04 & $0.3546^{\mathrm{N} . \mathrm{S}}$ \\
\hline$B \times D$ & 12 & 0.149 & 0.0124 & 1.23 & $0.2769^{\mathrm{N} . \mathrm{S}}$ \\
\hline $\mathrm{B} \times \mathrm{A}$ & 12 & 0.230 & 0.0191 & 1.90 & $0.1485^{\mathrm{N} . \mathrm{S}}$ \\
\hline$S \times D$ & 6 & 0.063 & 0.0104 & 1.04 & $0.4095^{\mathrm{N} . \mathrm{S}}$ \\
\hline $\mathrm{S} \times \mathrm{A}$ & 6 & 0.037 & 0.0062 & 0.61 & $0.7191^{\mathrm{N} . \mathrm{S}}$ \\
\hline $\mathrm{D} \times \mathrm{A}$ & 4 & 0.035 & 0.0088 & 0.87 & $0.4837^{\mathrm{N} . \mathrm{S}}$ \\
\hline $\mathrm{B} \times \mathrm{S} \times \mathrm{D}$ & 36 & 0.575 & 0.0160 & 1.59 & $0.1486^{\mathrm{N} . \mathrm{S}}$ \\
\hline $\mathrm{B} \times \mathrm{S} \times \mathrm{A}$ & 36 & 0.397 & 0.0110 & 1.09 & $0.3650^{\text {N.S }}$ \\
\hline $\mathrm{B} \times \mathrm{D} \times \mathrm{A}$ & 24 & 0.315 & 0.0131 & 1.30 & $0.1946^{\mathrm{N} . \mathrm{S}}$ \\
\hline $\mathrm{S} \times \mathrm{D} \times \mathrm{A}$ & 12 & 0.104 & 0.0087 & 0.86 & $0.5906^{\mathrm{N} . \mathrm{S}}$ \\
\hline $\mathrm{B} \times \mathrm{S} \times \mathrm{D} \times \mathrm{A}$ & 72 & 0.876 & 0.0121 & 1.19 & $0.4635^{\mathrm{N} . \mathrm{S}}$ \\
\hline Error & 756 & 7.63 & 0.0101 & - & - \\
\hline Total & 1007 & 137.35 & - & - & - \\
\hline
\end{tabular}

Table 6a. Comparison of individual treatment means for yarn elongation $(\%)$

\begin{tabular}{llll}
\hline \hline $\begin{array}{l}\text { Blend ratio } \\
(B)\end{array}$ & $\begin{array}{l}\text { Delivery } \\
\text { speed } \\
\text { (S) }\end{array}$ & $\begin{array}{l}\text { Spindle } \\
\text { diameter } \\
\text { (D) }\end{array}$ & $\begin{array}{l}\text { Distance } \\
\text { between } \\
\text { front roll } \\
\text { and spindle } \\
\text { (A) }\end{array}$ \\
\hline $\mathrm{B}_{1}=8.7506 \mathrm{a}$ & $\mathrm{S}_{1}=7.9513$ & $\mathrm{D}_{1}=7.6686$ & $\mathrm{~A}_{1}=7.7584 \mathrm{~b}$ \\
$\mathrm{~B}_{2}=8.4569 \mathrm{~b}$ & $\mathrm{~S}_{2}=7.8205$ & $\mathrm{D}_{2}=7.8128$ & $\mathrm{~A}_{2}=7.9470 \mathrm{a}$ \\
$\mathrm{B}_{3}=8.2091 \mathrm{c}$ & $\mathrm{S}_{3}=7.6843$ & $\mathrm{D}_{3}=7.8504$ & $\mathrm{~A}_{3}=7.6263 \mathrm{c}$ \\
$\mathrm{B}_{4}=7.8614 \mathrm{~d}$ & $\mathrm{~S}_{4}=7.6529$ & - & - \\
$\mathrm{B}_{5}=7.3986 \mathrm{e}$ & - & - & - \\
$\mathrm{B}_{6}=7.0378 \mathrm{f}$ & - & - & - \\
$\mathrm{B}_{7}=6.7264 \mathrm{~g}$ & - & - & - \\
\hline \hline
\end{tabular}

Any two values not sharing a letter in common differ significantly at 0.05 level of probability.

Duncan's multiple range test and the comparison of individual treatment means for distance between front roll and spindle are presented in Table 6a. These show that the mean values of yarn elongation for $\mathrm{A}_{1}, \mathrm{~A}_{2}$ and $\mathrm{A}_{3}$ are 7.76, 7.94 and $7.62(\%)$, respectively. $\mathrm{A}_{2}$ gave the best results with respect to yarn elongation. These findings are closely related to the observations that the closer (optimum) the first nozzle is positioned to the nip of the front roller, the greater the increase in elongation (Tyagi and Salhotra, 1996).

\section{Conclusion}

The study revealed that different blend ratios of polyester and cotton and the MVS spindle diameter had significant effects upon the tensile properties of yarn, particularly with respect to single end strength and RKM. Elongation was not affected by spindle diameter. Delivery speed and distance to the front roller had little or no effect on tensile properties of cotton / polyester blend yarns, although elongation was affected significantly by the distance from the front roller to spindle. It shows that different polyester / cotton blend ratios, spindle diameter and distance between front roll and spindle significantly affect the tensile properties of MVS yarn.

\section{References}

ASTM. 2008. Standard test method for measurement of yarn properties. ASTM Designation: D-2256. American Society for Testing and Materials, Philadelphia, USA.

Basal, G., Oxenham, W. 2006. Effects of some process parameters on the structure and properties of vortex spun yarn. Textile Research Journal, 76: 492-499.

Gordon, S. 2002. The effect of short fibre and neps on Murata vortex spinning. The Australian Cottongrower, 23: 28-35.

Hussain, K. 1981. Some studies in blending of medium staple Pakistani cotton with polyester and its influence on spinning quality. M.Sc. Thesis, pp. 44-47, Department of Fibre and Textile Technology, University of Agriculture, Faisalabad.

Montgomery, D.C. 2009. Design and Analysis of Experiments. pp. 477-513, $7^{\text {th }}$ edition, John Wiley \& Sons, Inc., UK.

Nawaz, S.M., Shahbaz, B., Chattah, A.A. 1999. Influence of fixed flat segments at conventional card upon yarn imperfections. Pakistan Textile Journal, 48: 43-45.

Ortlek, H.G., Nair, F., Kilik, R., Guven, K. 2008. Effect of spindle diameter and spindle working period on the properties of $100 \%$ viscose MVS yarns. Fibres \& Textiles in Eastern Europe, 16: 17-20.

Ortlek, H.G., Ulku, S. 2005. Effect of some variables on properties of $100 \%$ cotton vortex spun yarn. Textile Research Journal, 75: 458-461.

Oxenham, W. 2003. Developments in spinning. An 
overview of yarn formation technologies. Textile World. May, 2003 [online]. Available at: http://www. textileworld.com/News.htm?CD=1726\&ID=4676.

Shahzad, F.S. 2003. Comparison of knitted fabric from air-jet and ring spun yarn by selecting multiple blend ratios of cotton and polyester. M.Sc. Thesis, pp. 31-33, Department of Fibre and Textile Technology, University of Agriculture, Faisalabad. Tyagi, G.K., Salhotra, K.R. 1996. Yarn characters under steam relaxation. Textile in Asia, 27: 41-71. 